\title{
INTER-RATER RELIABILITY BETWEEN PARAMEDICS AND NEUROLOGISTS IN ASSESSMENT OF HEMIPLEGIA IN ACUTE STROKE DID NOT IMPROVE AFTER RE-EDUCATION
}

M. Cabal ${ }^{1}$, D. Holes ${ }^{2,3}$, J. Kral' ${ }^{1,4,5}$, D. Vaclavik ${ }^{6}$, L. Klecka7, R. Mikulik,8, M. Bar,5

${ }^{1}$ Comprehensive Stroke Centre- University Hospital Ostrava, Department of Neurology, Ostrava, Czech Republic, ${ }^{2}$ Emergency Medical Service, Emergency, Moravian-Silesian Region, Czech Republic, ${ }^{3}$ Comenius University in Bratislava, Jessenius Faculty of Medicine in Martin, Bratislava, Slovak Republic, ${ }^{4}$ St. Anne's University Hospital and Faculty of Medicine-Masaryk University, Department of Neurology, Brno, Czech Republic, ${ }^{5}$ Faculty of Medicine- Ostrava University, Department of Neurology and Psychiatry, Ostrava, Czech Republic, ${ }^{6}$ Ostrava Vitkovice Hospital, Agel Research and Training Institute, Ostrava, Czech Republic, ${ }^{7}$ Primary Stroke Centre-City Hospital Ostrava, Department of Neurology, Ostrava, Czech Republic, 8 International Clinical Research Centre-St. Anne's University Hospital, Neurology Department, Brno, Czech Republic.

\section{Background and Aims}

Reliable pre-hospital triage by paramedics is needed to select possible candidates with acute stroke for mechanical trombectomy and transfer them directly to the comprehensive cerebrovascular centre where then can receive such treatment.

Although optimal score has not been established, it is not clear what level of competency exists between paramedics for diagnosis of major neurological deficits.

The aim of our study was to define inter-rater reliability between paramedics and stroke neurologists for the presence of severe hemiparesis.

\section{Method}

It was a prospective, double phase, multicentre study.

During the first phase (April - October 2016), paramedics were educated to diagnose mild or severe hemiparesis via Internet e-learning. Their participation in the training was voluntary.

In the second phase (August-October 2017) paramedics were re-educated via webinars and examined straight after.

Agreement for degree of hemiparesis [NIHSS, item 4 and 5 , scoring 0-2 (none or mild) versus 3-4 (severe)] between paramedics (assessed during pre-hospital) and neurologists (assessed immediately after stroke centre admission) was analysed using the unweighted Kappa index.

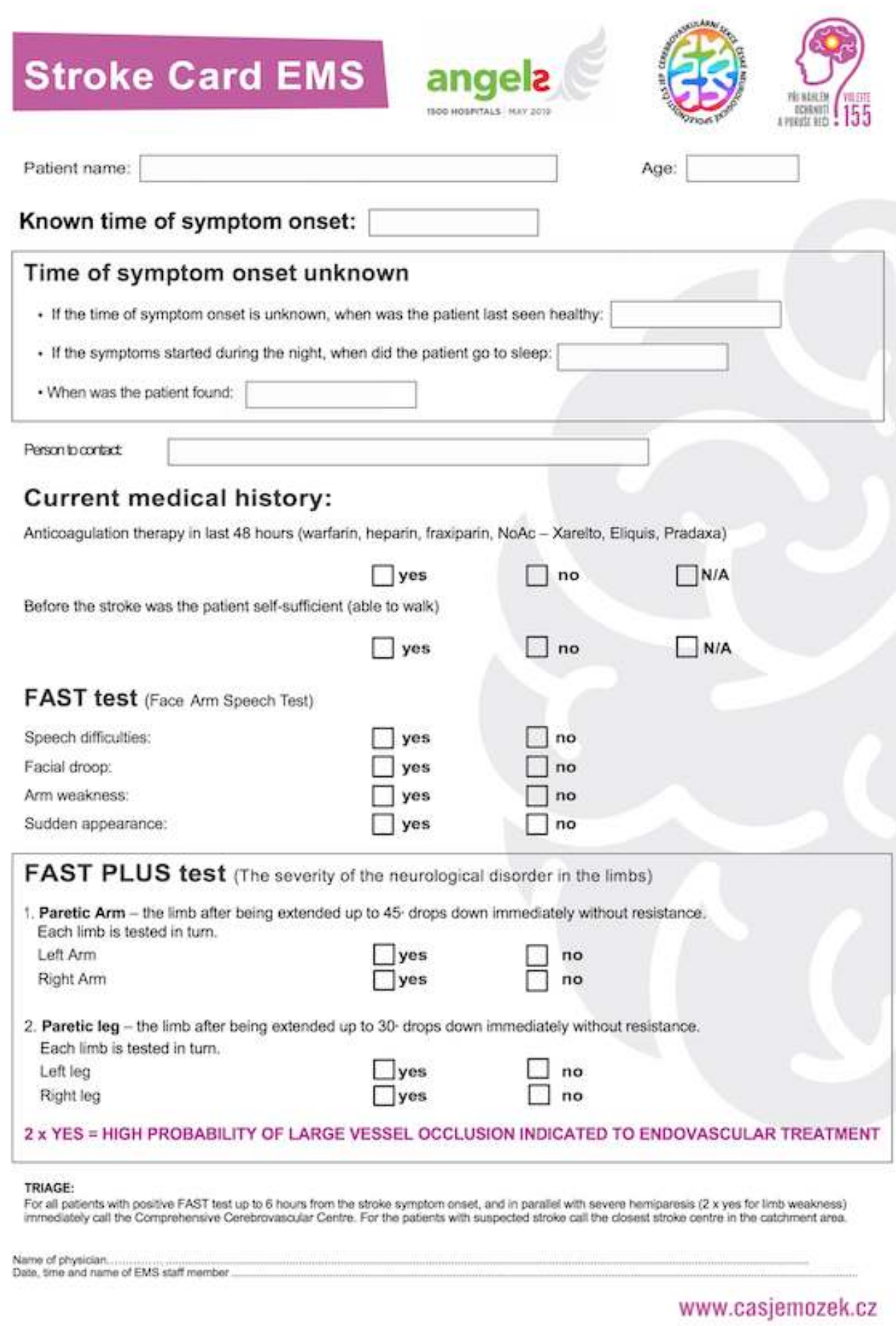

Results

During the first phase consecutive 422 (47\% of all) patients and during the second one 71 (65\%) patients were evaluated for the presence of hemiparesis by both paramedics (filling in the "stroke card") and neurologists. In first phase there were 215 men (51\%), average age 73, in second phase 35 men (50\%), average age 74.

In both phases the agreement between the paramedics and neurologists was moderate - in the first one kappa $0.54(95 \% \mathrm{Cl} 0.46-0.62)$ in the second kappa $0.43(95 \% \mathrm{Cl} 0.27-0.63)$.

\begin{tabular}{|l|c|c|}
\hline & First phase & Second phase \\
\hline Gender & $215 \mathrm{M}(51 \%)$ vs $207 \mathrm{~F}(49 \%)$ & $35 \mathrm{M}(50 \%)$ vs 36 F (50\%) \\
\hline Total number of patients & $898(100 \%)$ & $110(100 \%)$ \\
\hline Evaluated patients & $422(47 \%)$ & $71(65 \%)$ \\
\hline Total agreement & $76 \%$ & $72 \%$ \\
\hline Kappa index (unweighted) & $0.54(95 \% \mathrm{Cl} 0.46-0.62)$ & $0.43(95 \% \mathrm{Cl} 0.27-0.63)$ \\
\hline
\end{tabular}

\begin{tabular}{|l|l|l|}
\hline \multirow{2}{*}{ 2 $^{\text {ND }}$ PHASE } & \multicolumn{2}{|c|}{ NEUROLOGIST } \\
\hline PAREMEDICS & negative & $\begin{array}{l}\text { mono/ } \\
\text { hemiplegia }\end{array}$ \\
\hline negative & $19(27 \%)$ & $4(6 \%)$ \\
\hline $\begin{array}{l}\text { mono/ } \\
\text { hemiplegia }\end{array}$ & $16(23 \%)$ & $32(45 \%)$ \\
\hline
\end{tabular}

\section{Conclusion}

In our study, reliability of assessment of hemiplegia by paramedics was only moderate and was not improved by repeated training. More effective training of paramedics is needed especially with the prospect of clinical need for pre-hospital triage for mechanical thrombectomy. However, the co-operation with paramedics has improved - more "stroke cards" have been filled in and therefore more patients could have been evaluated. 